\title{
Chronic glucocorticoid treatment alters spontaneous pulsatile parathyroid hormone secretory dynamics in human subjects
}

Stefania Bonadonna, Anna Burattin, Monica Nuzzo, Giovanna Bugari ${ }^{1}$, Enrico Agabiti Rosei, Domenico Valle ${ }^{2}$, Nicoletta Iori ${ }^{2}$, John P Bilezikian ${ }^{3}$, Johannes D Veldhuis ${ }^{4}$ and Andrea Giustina

Department of Medical Sciences, University of Brescia, Brescia, Italy, ${ }^{1}$ 3rd Laboratory, Spedali Civili of Brescia, Brescia, Italy, ${ }^{2}$ Medical Division, Eli Lilly, Sesto Fiorentino, Florence, Italy, ${ }^{3}$ Department of Medicine, College of Physicians and Surgeons, Columbia University, New York, USA and ${ }^{4}$ Mayo Clinic, Rochester, Minnesota, USA

(Correspondence should be addressed to A Giustina, Endocrine Section, c/o 2a Medicina Spedali Civili; 25215 Brescia, Italy; Email: a.giustina@libero.it)

\begin{abstract}
Objective: Spontaneous parathyroid hormone (PTH) secretory dynamics include tonic and pulsatile components. It is not known how glucocorticoids might alter these secretory dynamics.

Design: The aim of our study was to evaluate spontaneous fluctuations in serum PTH levels in six adult male patients (aged 31-64 years) receiving chronic ( $>6$ months) therapy with glucocorticoids (daily dosage $>7.5 \mathrm{mg}$ of prednisone or dose equivalent of other corticosteroid) as compared with a control group of 10 age- and sex-matched normal subjects.

Methods: Peripheral venous blood sampling was performed every $3 \mathrm{~min}$ for $6 \mathrm{~h}$ from 0900 to $1500 \mathrm{~h}$. Plasma PTH release profiles were subjected to deconvolution analysis, a method that resolves measured hormone concentrations into secretion and clearance components, and to an approximate entropy (ApEn) estimate, that in turn provides an integrated measure of the serial regularity or orderliness of the release process.

Results: In the glucocorticoid-treated group, the PTH tonic secretory rate was reduced $(4.3 \pm 0.74$ vs $8.8 \pm 1.4 \mathrm{pg} / \mathrm{ml}$ per $\mathrm{min}$ in controls, $P=0.017)$. There was, however, an increase in the fractional pulsatile PTH secretion $(42 \pm 8.2$ vs $18.3 \pm 3.9 \mathrm{pg} / \mathrm{ml}$ per $\mathrm{min}, P=0.006)$ in glucocorticoid-treated vs normal subjects. Mean overall PTH concentration, as well as mean integrated area, was similar among normal and glucocorticoid-treated subjects.

Conclusions: These results demonstrate, for the first time, that chronic glucocorticoid treatment induces a redistribution of spontaneous PTH secretory dynamics by reducing the amount released in tonic fashion and increasing the amount released as pulses.
\end{abstract}

European Journal of Endocrinology 152 199-205

\section{Introduction}

Glucocorticoid-induced osteoporosis (GIO) is one of the most common causes of osteoporosis, trailing only postmenopausal and age-related osteoporosis in importance (1). The pathogenesis of GIO is multifactorial (2), including effects of glucocorticoids on gastrointestinal absorption of calcium, vitamin D metabolism, renal calcium handling, bone turnover itself and the hypothalamic-pituitary-gonadal axis. Most explanatory diagrams of GIO include a secondary rise in parathyroid hormone $(\mathrm{PTH})$ which, however, has recently been questioned (3). The putative compensatory increase in PTH is believed to be due to the effects of glucocorticoids in limiting calcium absorption in the gastrointestinal tract and in facilitating renal calcium excretion (4). Some studies have suggested that vitamin D deficiency or resistance could contribute to the reductions in calcium absorption or, conceivably, also lead more directly to PTH hypersecretion $(5,6)$.
Many hormones have a pusatile component to their secretory profile. (7-9). Reflecting episodic stimulatory input to the secretory gland, pulsatility is believed to modulate target organ responsiveness (7). Accurate characterization of hormonal pulses requires specific and sensitive assays, intensive schedules of blood sampling, and validated and objective methods of pulse analysis $(10,11)$. PTH has only been studied to a limited extent in this regard. Older reports have suggested that PTH is normally secreted in pulses in healthy young men and women $(12,13)$. Other studies have demonstrated that there is a significant diurnal rhythm of PTH, reflecting, perhaps, slight changes in serum calcium or phosphate concentration (14). Recent studies have established that, in healthy young subjects, PTH secretion has two major components: a predominantly tonic pattern of constant secretion and low amplitude pulses with high frequency (approximately every 15-20 min). In healthy individuals, pulsatile PTH secretion accounts for approximately 25\% 
of the total secreted PTH (15). No significant differences in these secretory dynamics have been observed between normal men and women (16) nor have there been any significant correlations between these patterns and the ambient PTH or ionized calcium concentration (17). In a disorder such as postmenopausal osteoporosis, however, dampened PTH pulsatility has been reported in some but not all early studies (13, 14, 17). Pulsatile (once daily) administration of PTH in low doses can be associated in animals and in human subjects with a preferential stimulation of new bone formation $(18-22)$. No data are so far available on the effect of chronic glucocorticoid excess on spontaneous pulsatile PTH secretion in human subjects. The aim of our study was to evaluate spontaneous fluctuations of PTH in patients chronically treated with pharmacological amounts of glucocorticoids.

\section{Materials and methods}

\section{Subjects}

Six adult male patients (age range 31-64 years) being treated with chronic glucocorticoid therapy $(>6$ months; daily dosage $7.5 \mathrm{mg}$ or more of prednisone deltacortene (Bruno Farmaceutica, Rome, Italy) or its dose equivalent) and ten normal subjects, matched for age and sex, were studied after they had given written informed consent. The clinical characteristics of the patients and the controls are reported in Table 1. Three of the six patients had rheumatic diseases (two had systemic lupus erythematosus and one had polymyalgia rheumatica). The mean duration of the treatment was 17.5 months and the mean daily dose of prednisone was $10 \mathrm{mg}$. Protocols were approved by the local Ethics Committee.

\section{Experimental design}

Biochemical assessment Each glucocorticoid-treated patient had blood fasting samples taken for the measurement of electrolytes, creatinine, phosphorus, albumin, protein and 25-hydroxyvitamin D. A 24-h urine sample was collected for the measurement of calcium excretion. A blood and urine sample was also collected from these patients for the assay of markers of bone metabolism (osteocalcin, bone-specific alkaline phosphatase activity (BSAP) and deoxypyridinoline (DPD)). All study subjects (glucocorticoid-treated and controls) were admitted to the hospital at $0830 \mathrm{~h}$. A venous catheter was placed in an ante-cubital vein and $2 \mathrm{ml}$ blood was withdrawn every $3 \mathrm{~min}$ for $6 \mathrm{~h}$ from 0900 to $1500 \mathrm{~h}$. Subjects, fasted since midnight, were not allowed to eat during the protocol but they were allowed free access to water. They remained recumbent during the study.

Assays Hematocrit, electrolyte, creatinine, calcium, phosphorus, albumin and protein levels were measured by Auto Analyser methods (Technicon Instruments Corp., Tarrytown, NY, USA). Urinary DPD was evaluated by Pyrilinks-D (Metra Biosystem, Mountain View, CA, USA; nl range, $2.3-6.7 \mu \mathrm{M} / \mathrm{mM}$ creatinine) and BSAP activity was measured by Alkaphase-B (Metra Biosystem; nl range: 10-50 IU/l). Serum 25-hydroxyvitamin D was measured by RIA. All blood samples were analyzed in duplicate for PTH using an immunoradiometric assay (Nichols Allegro, San Juan Capistrano, CA, USA). Assay sensitivity was $1 \mathrm{pg} / \mathrm{ml}$; intraand interassay coefficients of variation were $4 \%$ and $6 \%$ respectively. All samples from an individual subject were run in the same assay.

Deconvolution analysis Multiple parameter deconvolution was applied to each subject's plasma PTH concentration profile as previously described (15). The following parameters were estimated: tonic PTH secretion rate ( $\mathrm{pg} / \mathrm{ml}$ per min), initial plasma PTH concentration $(\mathrm{pg} / \mathrm{ml})$, secretory burst half-duration (min) and total number of significant secretory bursts. The half-life for PTH clearance was assumed to be $2.5 \mathrm{~min}$. The dose-dependent intra-assay variance associated with sample means (assay duplicates) was used in an inverse weighting function when calculating the best-fit secretory values. The plasma PTH release profiles were also subjected to an approximate entropy (ApEn) estimate, which provides an ensemble measure of the serial regularity or orderliness of the release process (15).

Table 1 Clinical characteristics of the male patients and the ten male control subjects studied.

\begin{tabular}{|c|c|c|c|c|c|}
\hline Patient number & Age (years) & $\begin{array}{l}\text { Body mass } \\
\text { index }\left(\mathrm{kg} / \mathrm{m}^{2}\right)\end{array}$ & Diagnosis & $\begin{array}{l}\text { Prednisone } \\
\text { dose (mg/day) }\end{array}$ & $\begin{array}{c}\text { Duration of } \\
\text { therapy (months) }\end{array}$ \\
\hline 1 & 36 & 24 & Sarcoidosis & 10 & 24 \\
\hline 2 & 54 & 23 & SLE & 7.5 & 36 \\
\hline 3 & 42 & 24 & Bechet & 7.5 & 6 \\
\hline 4 & 60 & 21 & Polymyalgia & 15 & 9 \\
\hline 5 & 64 & 22 & SLE & 7.5 & 24 \\
\hline Mean \pm S.E.M. & $52 \pm 4.84$ & $24.17 \pm 0.65$ & & $10 \pm 1.41$ & $17.5 \pm 5.54$ \\
\hline Controls & $36-58$ & $22-26$ & & & \\
\hline
\end{tabular}




\section{Statistical analyis}

Values are reported as means \pm S.E.M. PTH secretory parameters derived from deconvolution analysis and ApEn were compared among the group of the glucocorticoidtreated patients and the controls by ANOVA. PTH fractional pulsatile secretion was correlated with clinical parameters with linear regression analysis.

\section{Results}

\section{Bone metabolism data}

Mean 25-hydroxyvitamin D and serum and urinary calcium levels were in the normal reference range (Table 2). One patient was below the normal reference range for our laboratory at $13 \mathrm{ng} / \mathrm{ml}(\mathrm{nl}: 15-75)$ and

Table 2 Baseline bone metabolic parameters.

\begin{tabular}{|c|c|c|c|c|c|c|}
\hline $\begin{array}{l}\text { Patient } \\
\text { number }\end{array}$ & $\begin{array}{c}\text { DPD } \\
(\mu \mathrm{M} / \mathrm{mM} \text { creatinine })\end{array}$ & $\begin{array}{l}\text { Osteocalcin } \\
(\mu \mathrm{g} / \mathrm{l})\end{array}$ & $\begin{array}{l}\text { BSAP } \\
(I U / I)\end{array}$ & $\begin{array}{l}\text { 25-OH Vit. D } \\
\text { (ng/ml) }\end{array}$ & $\begin{array}{l}\text { Calcium in serum } \\
\qquad(\mathrm{mg} / \mathrm{dl})\end{array}$ & $\begin{array}{l}\text { Calcium in } 24 \mathrm{~h} \text { urine } \\
(\mathrm{mg} / 24 \mathrm{~h})\end{array}$ \\
\hline 1 & 5 & 12 & 14 & 13 & 9.2 & 255 \\
\hline 2 & 4.4 & 6 & 12 & 31 & 9.6 & 220 \\
\hline 3 & 5.2 & 7.1 & 16 & 18 & 9.4 & 240 \\
\hline 4 & 4.7 & 5 & 18 & 21 & 9.5 & 190 \\
\hline 5 & 3.1 & 4.6 & 10 & 24 & 9.1 & 210 \\
\hline 6 & 5.9 & 3 & 8 & 16 & 8.9 & 155 \\
\hline Mean士S.E.M & $4.72 \pm 0.4$ & $6.28 \pm 1.4$ & $13 \pm 2$ & $20.5 \pm 1.1$ & $9.28 \pm 0.11$ & $211 \pm 16$ \\
\hline $\mathrm{nl}$ range & $<7$ & $7-50$ & $10-50$ & $15-75$ & $8-10$ & $100-300$ \\
\hline
\end{tabular}

25-OH Vit. D, 25-hydroxyvitamin D; BSAP, bone specific alkaline phosphatase.

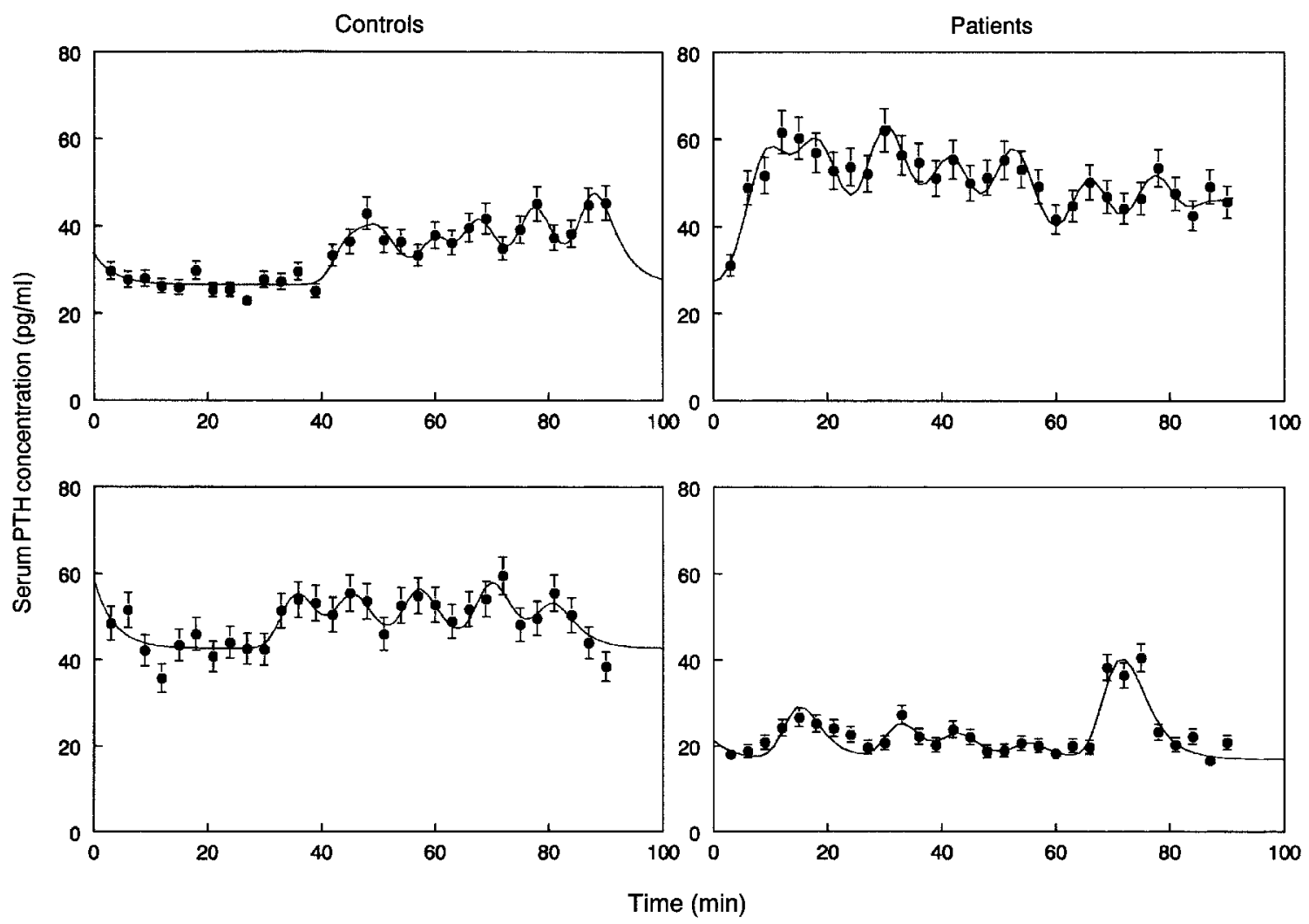

Figure 1 Illustrative profiles of serum PTH concentrations in two different representative control and glucocorticoid-treated subjects over the first $100 \mathrm{~min}$ of the sampling period. Serum PTH concentrations are shown by a continuous line through the data points that represent the calculated fit as predicted from the specific PTH secretory measures estimated by deconvolution in that individual. The figure shows sample standard deviation as recalculated from the duplicates using errors inherent in the standard curve as described in Giustina \& Veldhuis (7). The reported sampling period is considered to be representative of the entire study period as well as to allow a better depiction of PTH spontaneous secretory activity. 
another two subjects had 25-hydroxyvitamin D levels below $20 \mathrm{ng} / \mathrm{ml}$, the newly regarded lower limit of the physiologic range. Markers of bone turnover were normal for bone resorption (DPD) but it is noteworthy that the bone formation marker, serum osteocalcin, was either frankly low or in the low normal range. Similarly, BSAP was generally in the low normal range. These bone marker data are consistent with the expectation that patients on chronic glucocorticoid therapy are in a low bone turnover state.

\section{PTH secretory characteristics}

Representative patterns of absolute and deconvoluted PTH levels in two representative patients and control subjects are shown in Figs 1 and 2. Mean PTH secretory parameters derived from deconvolution analysis are listed in Table 3. PTH tonic secretory rate was $4.3 \pm 0.74 \mathrm{pg} / \mathrm{ml}$ per min in the glucocorticoidtreated group, significantly lower than the rate in the control group, $8.8 \pm 1.4 \mathrm{pg} / \mathrm{ml}$ per min $(P=0.017)$. Plasma PTH tonic secretory rate derived from deconvolution analysis in the glucocorticoid-treated group and in the control group is shown in Fig. 3a. The fractional pulsatile PTH secretion was $42 \pm 8.2 \%$ and $18.3 \pm 3.9 \%$ respectively in the glucocorticoid-treated and control groups $(P=0.006)$. The number of PTH bursts was not significantly higher in patients vs controls. PTH peaks had slightly, even though not significantly longer, half-duration and larger total mass in glucocorticoid-treated patients vs controls, whereas the interval between peaks was shorter and peak amplitude tended to be greater in control vs glucocorticoid-treated patients. ApEn, a measure of orderliness of PTH secretion, was similar for patients and controls. Fractional pulsatile PTH secretion rate derived from deconvolution analysis in the two groups is shown in Fig. $3 \mathrm{~b}$. Mean percentage PTH secretion in pulses was more than double in glucocorticoid-treated patients than in controls. Mean overall PTH concentration and mean integrated area were not significantly different in normal subjects as compared with glucocorticoid-treated patients (Fig. 3c). No correlations were found between PTH secretion and other clinical and biochemical variables.

\section{Discussion}

Recent pathophysiological animal and human models of glucocorticoid action in bone describe two phases: a short-term increase in bone resorption and a much longer, more profound reduction in bone formation
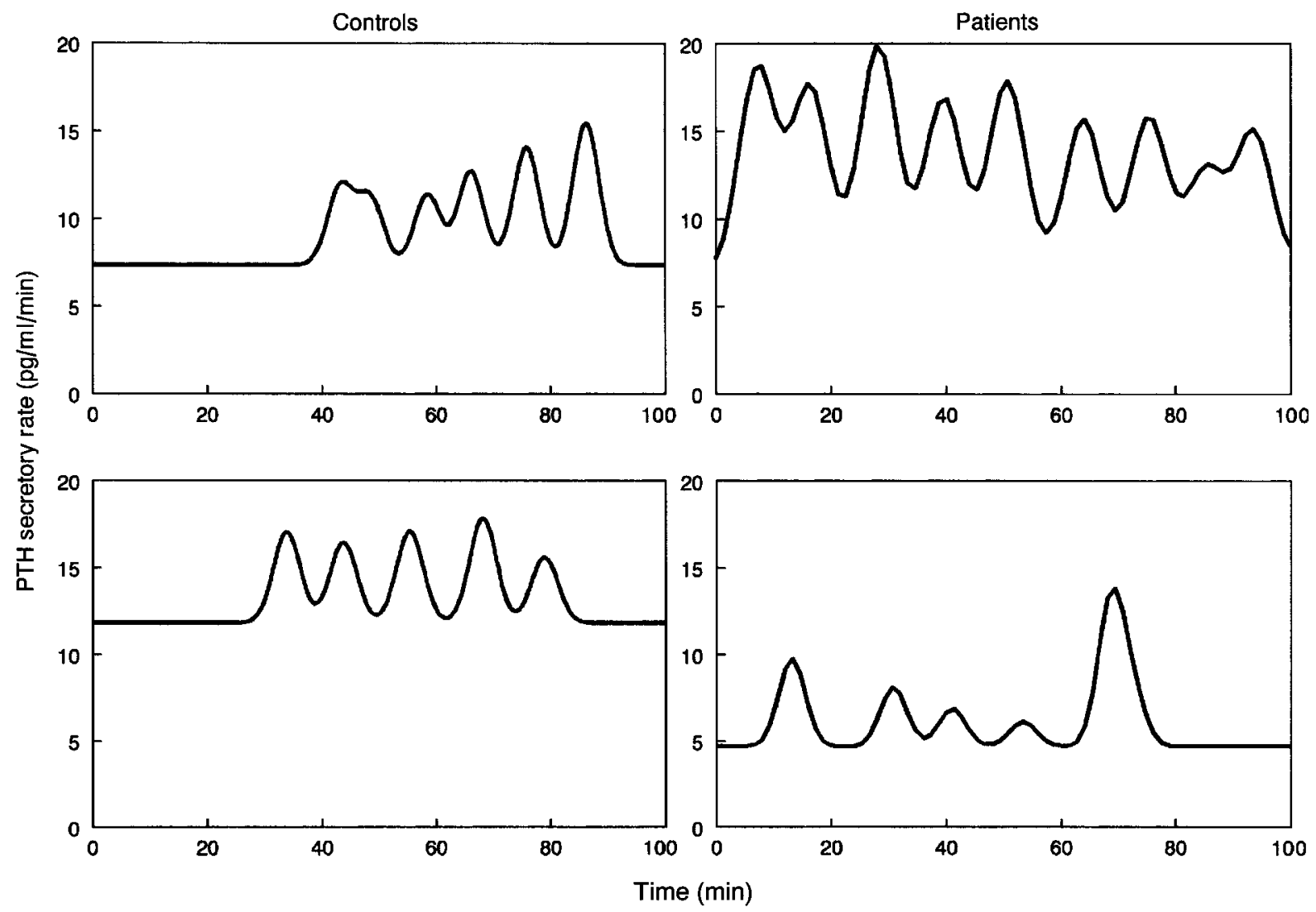

Figure 2 Illustrative profiles of resolved PTH secretory bursts in two different representative control and glucocorticoid-treated subjects (same as Fig. 1). The resolved PTH secretory function is a plot of the calculated PTH secretion rate over time. 
Table 3 Measures of spontaneous PTH secretory pattern estimated by deconvolution analysis in the six patients treated with glucocorticoid with respect to a control group of ten normal subjects. Values are expressed as means \pm S.E.M.

\begin{tabular}{lcc}
\hline Parameters & Controls & Patients \\
\hline Tonic secretion rate (pg/ml per min) & $8.8 \pm 1.4$ & $4.3 \pm 0.74$ \\
Half-duration (min) & $7 \pm 1.6$ & $9.6 \pm 1.2$ \\
Bursts (total number) & $6.1 \pm 0.44$ & $5.8 \pm 0.3$ \\
Interval (min) & $12.8 \pm 1.3$ & $15.4 \pm 0.69$ \\
Mass (pg per pulse) & $26.5 \pm 4.3$ & $46 \pm 9.1$ \\
Pulse secretary rate (pg/ml per min) & $154 \pm 23$ & $269 \pm 62$ \\
Total pulsatile release (pg/ml) & $944 \pm 12$ & $637 \pm 74$ \\
$\%$ Pulsatile & $18.3 \pm 3.9$ & $42 \pm 8.2$ \\
ApEn ratio & $0.853 \pm 0.047$ & $0.891 \pm 0.063$ \\
Mean concentration $(\mathrm{pg} / \mathrm{ml})$ & $38 \pm 4.8$ & $28 \pm 4.8$ \\
Integrated area $(\mathrm{pg} / \mathrm{ml} \mathrm{per} 6 \mathrm{~h})$ & $3286 \pm 422$ & $2407 \pm 418$ \\
\hline
\end{tabular}

(3, 23-25). Non-skeletal physiological actions on the gastrointestinal tract, to reduce intestinal calcium absorption (26) and on the kidney, to induce hypercalciuria (27), have skeletal consequences. The effects of glucocorticoids in inhibiting the growth hormoneinsulin-like growth factor-I (IGF-I) axis $(28,29)$ and the hypothalamic-pituitary-gonadal axis also have skeletal consequences $(30-33)$.

These direct and indirect effects of glucocorticoids could have effects on the parathyroid glands. The parathyroid glands are believed to be targets of glucocorticoid actions, but the literature has not been consistent. Slovik et al. (34) found normal PTH levels in asthmatic patients on long-term and short-term glucocorticoid treatment. PTH levels in 22 women with rheumatoid arthritis were not influenced by low dose prednisone (35). Even when women were given higher amounts of prednisone chronically, PTH levels were not different from age-matched controls (36). The same observations were made by Hattersley et al. (37) who studied patients treated with glucocorticoids for chronic obstructive pulmonary disease. In contrast, other reports have associated long-term glucocorticoid use with elevated circulating PTH levels $(1,2,27)$. One reason for these contradictory results may be due to the fact that single random measurements do not reflect the overall pattern of PTH secretion in a given subject nor do they give any insight into possible abnormalities in the secretory dynamics of PTH as a consequence of the glucocorticoids. This point is particularly relevant since it is now known that PTH is secreted both in low amplitude pulses and in a tonic secretory state $(16,17)$. Until the results of this study, no comparable data were available on pulsatile vs tonic secretory PTH dynamics in patients chronically treated with glucocorticoids. The results from our study document that in patients chronically treated with glucocorticoids there is a reduced amount of PTH secreted in the tonic mode as compared with normal subjects. Our results have also demonstrated an increase in the fractional pulsatile PTH secretion
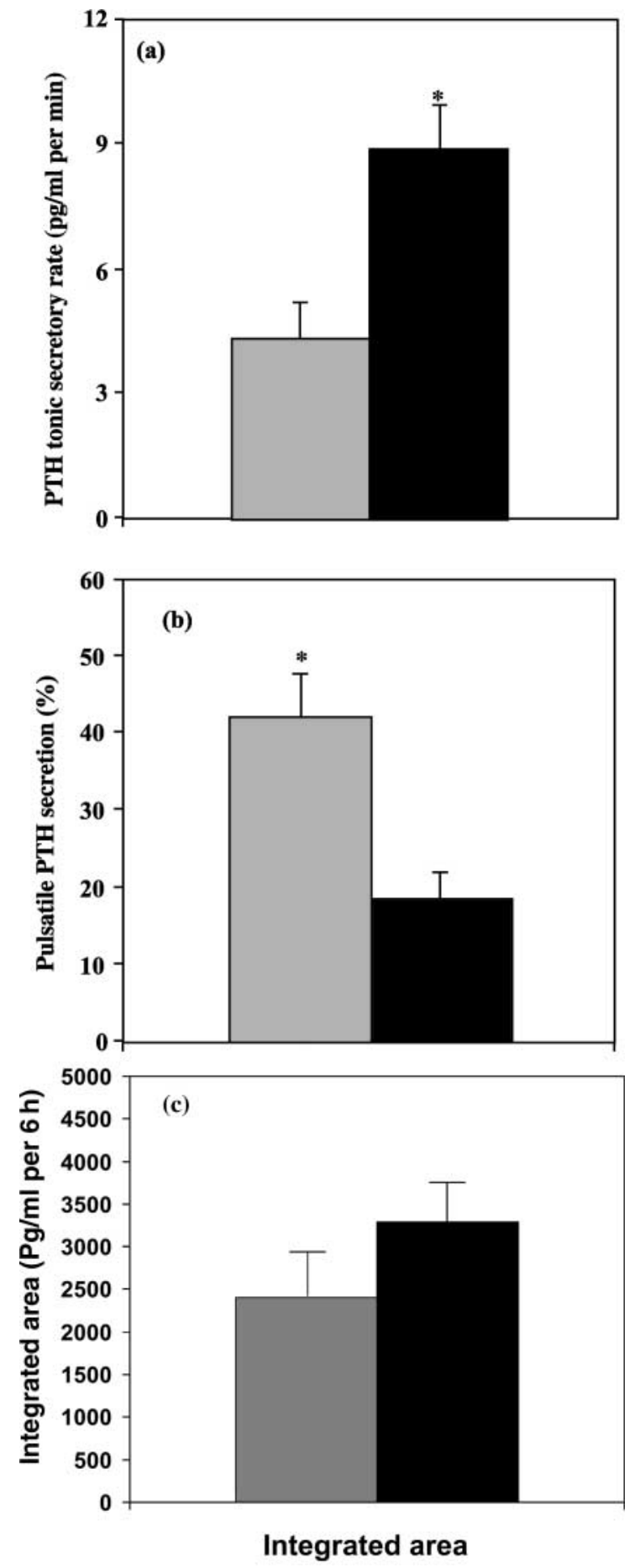

GC-treated $\square$ Control

Figure 3 (a) PTH tonic secretory rate in the glucocorticoid-treated group (shaded bars) and in the controls (solid bars). ${ }^{*} P<0.05$. (b) Percent of PTH secreted in pulses vs overall PTH secretory rate in glucocorticoid-treated subjects (shaded bars) and in the controls (solid bars). ${ }^{*} P>0.01$. (c) Mean integrated area in normal subjects (solid bars) vs glucocorticoid-treaded patients (shaded bars). 
in patients treated with chronic glucocorticoid therapy as compared with normal subjects. The increase in pulsatility dynamics is associated with a reduction in the amount of PTH released in the tonic mode.

These abnormalties in PTH secretory dynamics may well relate to observations in animals and now in human subjects that clearly show differences in PTH actions as a function of how it is administered (20, 22,38 ). This concept may provide an interesting rationale for explaining the efficacy of exogenous intermittent PTH treatment in glucocorticoid-induced osteoporosis (39). Intermittent administration of PTH may provide patients with peaks of PTH that are much larger than those that could be obtained by limited intrinsic compensatory mechanisms.

The regulatory physiology by which glucocorticoids induce a redistribution of spontaneous PTH secretion is not known. Even if there were subtle abnormalities in ionized calcium, Samuels et al. $(16,17)$ have previously shown that no correlation exists between ionized calcium levels and serum PTH spontaneous secretion. Levels of vitamin D in the lower range of normal could conceivably be a secretory trigger. Finally, it is possible that glucocorticoids act directly at the parathyroid gland to affect PTH secretory dinamics. Thus, glucocorticoids may have actions that govern more the secretory behavior of PTH than the actual amount secreted over a period of time (16). Another possibility to be tested is that glucocorticoids either directly or indirectly alter the ratio between the intact molecule, $\mathrm{PTH}(1-84)$, and a large amino-terminally truncated form, $\operatorname{PTH}(7-84)$, that is present both in the parathyroids and in the circulation. Central or peripheral alteration in the ratio of $\mathrm{PTH}(1-84) / \mathrm{PTH}(7-84)$ could have important pathophysiological implications. Since the assay used in this study detects both full-length intact molecule as well as $\operatorname{PTH}(7-84)$, more specific assays will be needed to investigate this point.

It has been reported that glucocorticoids may affect GH pulsatility (40). It has also been reported that estrogen replacement treatment reduces PTH pulsatility (41). It is of interest, therefore, that an inhibitor of bone resorption, estrogen, has one effect on PTH pulsatility while an inhibitor of bone formation, glucocorticoids, has the opposite effect, namely to increase PTH pulsatility. Secretory dynamics of PTH could reflect effects at the level of bone metabolism with signals generated from bone to the parathyroids. Two such systems that could be involved are receptor activator nuclear factor-kappaB osteoprotegerin and IGF-I in which glucocorticoids and PTH have diametrically opposite effects $(18,42,43)$.

We have shown in this study that glucocorticoids profoundly affect the secretory dynamics of PTH. Whether the redistribution of PTH secreted in tonic or pulsatile compartments is going to be shown to have primary or secondary effects on bone metabolism remains to be demonstrated by further investigation.

\section{Acknowledgements}

We are indebted to Dr R Carpinteri, D Godi, F Manelli and S Villa for their help. We also thank G Milani for her technical work. We are also grateful to GISGO and Centro di Ricerca sull'Osteoporosi, Università degli Studi di Brescia - Eulo for partially supporting the study.

\section{References}

1 Manelli F \& Giustina A. Glucocorticoid-induced osteoporosis. Trends in Endocrinology and Metabolism $20001179-85$.

2 Canalis E \& Giustina A. Glucocorticoid-induced osteoporosis: summary of a workshop. Journal of Clinical Endocrinology and Metabolism $2001 \mathbf{8 6} 5681-5685$.

3 Rubin MR \& Bilezikian JP. The role of parathyroid hormone in the pathogenesis of glucocorticoid-induced osteoporosis: a re-examination of the evidence. Journal of Clinical Endocrinology and Metabolism $2002 \mathbf{8 7} 4034-4041$.

4 Manolagas SC, Weinstein RS, Jilka RL \& Parfitt AM. Parathyroid hormone and corticosteroid-induced osteoporosis. Lancet 1998 352 1327-1328.

5 Cosman F, Nieves J, Herbert J, Shen V \& Lindsay R. High-dose glucocorticoids in multiple sclerosis patients exert direct effects on the kidney and skeleton. Journal of Bone and Mineral Research $199491097-1105$.

6 Gram J, Junker P, Nielsen HK \& Bollerslev J. Effects of short-term treatment with prednisone and calcitriol on bone and mineral metabolism in normal men. Bone 199823 297-302.

7 Giustina A \& Veldhuis J. Pathophysiology of the neuroregulation of growth hormone secretion in experimental animals and the human. Endocrine Reviews 199819 717-797.

8 Samuels MH, Veldhuis JD, Henry P \& Ridgway EC. Pathophysiology of pulsatile and copulsatile release of thyroid-stimulating hormone, luteinizing hormone, follicle-stimulating hormone and alpha-subunit. Journal of Clinical Endocrinology and Metabolism $199071425-432$.

9 Iranmanesh A, Lizzarralde G, Short D \& Veldhuis JD. Intensive venous sampling paradigms disclose high frequency adrenocorticotropin release episodes in normal men. Journal of Clinical Endocrinology and Metabolism 199071 1276-1283.

10 Giustina A, Girelli A, Alberti D, Bossoni S, Buzi F, Doga M, Schettino M \& Wehrenberg WB. Effects of pyridostigmine on spontaneous and growth hormone-releasing hormone stimulated growth hormone secretion in children on daily glucocorticoid treatment after liver transplantantion. Clinical Endocrinology $199135491-498$.

11 Giustina A, Scalvini T, Tassi C, Desenzani P, Poiesi C, Weherenberg WB, Rogol AD \& Veldhuis JD. Maturation of the regulation of growth hormone secretion in young males with hypogonadotropic hypogonadism pharmacologically exposed to progressive increments in serum testosterone. Journal of Clinical Endocrinology and Metabolism 199782 1210-1219.

12 Harms HM, Kaptaina U, Kulpmann RW, Brabant G \& Hesch RD. Pulse amplitude and frequency modulation of parathyroid hormone in plasma. Journal of Clinical Endocrinology and Metabolism $198969843-851$.

13 Kitamura N, Shigeno C, Shiomi K, Lee K, Otha S, Sone T, Katsushima K, Tadamura E, Kousaka T, Yamamoto I et al. Episodic fluctuation in serum intact parathyroid hormone concentration in men. Journal of Clinical Endocrinology and Metabolism $199070252-263$.

14 Calvo MS, Eastell R, Offord KP, Bergstralh EJ \& Burrit MF. Circadian variation in ionized calcium and intact parathyroid hormone: evidence for sex differences in calcium homeostasis. Journal of Clinical Endocrinology and Metabolism 199172 69-76. 
15 Schmitt CP, Schaefer F, Bruch A, Veldhuis JD, Schmidt-Gayk H, Stein G, Ritz E \& Mehls O. Control of pulsatile and tonic parathyroid hormone secretion by ionized calcium. Journal of Clinical Endocrinology and Metabolism 199681 4236-4243.

16 Samuels MH, Veldhuis J, Cawley C, Urban RJ, Luther M, Bauer R \& Mundy G. Pulsatile secretion of parathyroid hormone in normal young subjects: assessment by deconvolution analysis. Journal of Clinical Endocrinology and Metabolism 199377 399-403.

17 Samuels MH, Veldhuis JD, Kramer P, Urban RJ, Bauer R \& Mundy G. Episodic secretion of parathyroid hormone in post-menopausal women: assessment by deconvolution analysis and approximate entropy. Journal of Bone and Mineral Research 199312 616-623.

18 Mahoncy CA \& Nissenson RA. Canine renal receptors for parathyroid hormone: down regulation in vivo by exogenous parathyroid hormone. Journal of Clinical Investigation 1983 72 411-421.

19 Law WM Jr \& Heath H 3rd. Rapid development of renal resistance to low doses of synthetic bovine parathyroid hormone fragment 1-34. Dissociation of urinary cyclic adenosine monophosphate, phosphaturic, and calciuric responses. Journal of Clinical Investigation 198372 1106-1113.

20 Teitelbaum AP, Silve CM, Nyiredy KO \& Arnaud CD. Down-regulation of parathyroid hormone (PTH) receptors in cultured bone cells is associated with agonist-specific intracellular processing of PTH-receptor complexes. Endocrinology 1986118 595-602.

21 Tam CS, Heersche NM, Muray TM \& Parsons JA. Parathyroid hormones stimulates the bone apposition rate independently of its resorptive action: differential effects of intermittent and continuous administration. Endocrinology 1982110 506-512.

22 Neer RM, Arnaud CD, Zanchetta JR, Prince R, Gaich GA, Reginster JY, Hodsman AB, Eriksen EF, Ish-Shalom S, Genant HK, Wang O \& Mitlak BH. Effect of parathyroid hormone (134) on fractures and bone mineral density in postmenopausal women with osteoporosis. New England Journal of Medicine 2001 344 1434-1441.

23 Canalis E, Bilezikian J, Angeli A \& Giustina A. Perspective on glucocorticoid induced osteoporosis. Bone 200434 593-598.

24 Weinstein RS, Jilka RL, Parfitt AM \& Manolagas SC. Inhibition of osteoblastogenesis and promotion of apoptosis of osteoblasts and osteocytes by glucocorticoids. Potential mechanism of their deleterious effects on bone. Journal of Clinical Investigation 1998102 274-282.

25 Diamond T, Levy S, Day P, Barbagallo S, Manoharan A \& Kwan YK. Biochemical, histomorphometric and densitometric changes in patients with multiple myeloma: effects of glucocorticoid therapy and disease activity. British Journal of Haematology 1997 $97641-648$.

26 Gennari C. Differential effect of glucocorticoids on calcium absorption and bone mass. British Journal of Rheumatology 1993 32 (Suppl. 2) 11-14.

27 Reid IR. Glucocorticoid induced osteoporosis - mechanisms and management. European Journal of Endocrinology 1997137 209-217.

28 Giustina A \& Wehrenberg WB. The role of glucocorticoids in the regulation of growth hormone secretion. Trends in Endocrinology and Metabolism 19953 306-311.

29 Giustina A, Bossoni S, Bodini C, Girelli A, Balestrieri GP, Pizzocolo G \& Wehrenberg WB. Arginine normalizes the growth hormone (GH) response to GH-releasing hormone in adult patients receiving chronic daily immunosuppressive glucocorticoid therapy. Journal of Clinical Endocrinology and Metabolism 199274 1301-1305.
30 Reid IR, Wattie DJ, Evans MC \& Stapleton JP. Testosterone therapy in glucocorticoid-treated men. Archives of Internal Medicine 1996 $1561173-1177$.

31 Lukert BP, Johnson BE \& Robinson RG. Estrogen and progesterone replacement therapy reduces glucocorticoid-induced bone loss. Journal of Bone and Mineral Research 19927 1063-1069.

32 Ohlsson C, Bengtsson BA, Isaksson OG, Andreassen TT \& Slootweg M. Growth hormone and bone. Endocrine Reviews $19981955-79$.

33 Riggs BL, Khosla S \& Melton LJ III. Sex steroids and the construction and conservation of the adult skeleton. Endocrine Reviews $200223279-302$.

34 Slovik DM, Neer RM, Ohman JL, Lowell FC, Clark MB, Segre GV \& Potts JT. Parathyroid hormone and 25-hydroxyvitamin D levels in glucocorticoid-treated patients. Clinical Endocrinology 198012 $243-248$.

35 Leboff MS, Wade JP, Mackowiak S, el-Hajj Fuleihan G, Zangari M \& Liang MH. Low dose prednisone does not affect calcium homeostasis or bone density in postmenopausal women with rheumatoid arthritis. Journal of Rheumatology 199118 339-344.

36 Paz-Pacheco E, Fuleihan GE \& Leboff MS. Intact parathyroid hormone levels are not elevated in glucocorticoid-treated subjects. Journal of Bone and Mineral Research 199510 1713-1718.

37 Hattersley AT, Meeran K, Burrin J, Hill P, Shiner R \& Ibbertson HK. The effect of long- and short-term corticosteroids on plasma calcitonin and parathyroid hormone levels. Calcified Tissue International $1994 \mathbf{5 4} 198-202$.

38 Podbesek R, Edouard C, Meunier PJ, Parson JA, Reeve J, Stevenson RW \& Zanelli JM. Effects of two treatment regimens with synthetic human parathyroid hormone fragment on bone formation and the tissue balance of trabecular bone in greyhounds. Endocrinology 1983112 1000-1006.

39 Lane NE, Sanchez S, Modin GW, Genant HK, Pierini F \& Arnaud CD. Parathyroid homone treatment can reverse corticosteroid-induced osteoporosis. Results of a randomized controlled clinical trial. Journal of Clinical Investigation $1998 \mathbf{1 0 2}$ $1627-1633$.

40 Wehrenberg WB \& Giustina A. Neuroendocrine regulation of growth hormone secretion. In Neuroendocrinology in Physiology and Medicine, pp 181-195. Eds PM Conn \& ME Freeman. Totowa, NJ: Human Press Inc., 1999.

41 Harms HM, Neubauer O, Kayser C, Wustermann PR, Horn R, Brosa U, Schlinke E, Kulpmann WR, von zur Muhlen A \& Hesch RD. Pulse amplitude and frequency modulation of parathyroid hormone in early postmenopausal women before and on hormone replacement therapy. Journal of Clinical Endocrinology and Metabolism $1994 \mathbf{7 8} 48-52$.

42 Hofbauer LC, Gori F, Riggs BL, Lacey DL, Dunstan CR, Spelsberg TC \& Khosla S. Stimulation of osteoprotegerin ligand and inhibition of osteoprotegerin production by glucocorticoids in human osteoblastic linear cells: potential paracrine mechanisms of glucocorticoid-induced osteoporosis. Endocrinology 1999 $1404382-4389$.

43 Locklin RM, Khosla S \& Riggs BL. Mechanisms of biphasic anabolic and catabolic effects of parathyroid hormone (PTH) on bone cells. Bone 200128 S80.

Received 29 July 2004

Accepted 28 October 2004 